Old Dominion University

ODU Digital Commons

\title{
Plate Boundary and Triple Junction Control of Shatsky Rise Formation and Implications for Other Ocean Plateaus
}

Jennifer E. Georgen

Old Dominion University, jgeorgen@odu.edu

Katrina Shotorban

Old Dominion University, ashot001@odu.edu

Follow this and additional works at: https://digitalcommons.odu.edu/oeas_fac_pubs

Part of the Oceanography Commons

\section{Original Publication Citation}

Georgen, J. E., \& Shotorban, A. K. (2021). Plate boundary and triple junction control of Shatsky Rise formation and implications for other ocean plateaus. Geophysical Research Letters, 48(15), 1-8, Article e2021GL093150. https://doi.org/10.1029/2021GL093150

This Article is brought to you for free and open access by the Ocean \& Earth Sciences at ODU Digital Commons. It has been accepted for inclusion in OES Faculty Publications by an authorized administrator of ODU Digital Commons. For more information, please contact digitalcommons@odu.edu. 


\section{Geophysical Research Letters}

\section{RESEARCH LETTER \\ 10.1029/2021GL093150 \\ Key Points: \\ - Spreading center geometry and ridge migration of the Pacific-Izanagi- Farallon triple junction contributed to Tamu Massif formation \\ - A broad area of thin lithosphere at the Pacific-Izanagi-Farallon triple junction promoted spatially widespread mantle and plume melting \\ - This study provides a mechanism for why marine large igneous provinces are often developed near mid-ocean ridge triple junctions}

Correspondence to:

J. E. Georgen,

jgeorgen@odu.edu

Citation:

Georgen, J. E., \& Shotorban, A. K. (2021). Plate boundary and triple junction control of Shatsky Rise formation and implications for other ocean plateaus. Geophysical Research Letters, 48, e2021GL093150. https://doi. org/10.1029/2021GL093150

Received 8 MAR 2021 Accepted 3 JUL 2021
(C) 2021. American Geophysical Union. All Rights Reserved.

\section{Plate Boundary and Triple Junction Control of Shatsky Rise Formation and Implications for Other Ocean Plateaus}

\author{
Jennifer E. Georgen ${ }^{1}$ (i) and A. Katrina Shotorban ${ }^{1}$ \\ ${ }^{1}$ Department of Ocean and Earth Sciences, Old Dominion University, Norfolk, VA, USA
}

\begin{abstract}
In the study of marine large igneous provinces, investigations often focus on the importance of mantle plumes in generating excess magmatism. Few studies, however, have addressed the role of plate boundary processes in promoting widespread and extensive mantle melting. This study investigates how spreading center geometry may have facilitated the emplacement of Shatsky Rise, an oceanic plateau in the western Pacific Ocean. The largest structure within Shatsky Rise, Tamu Massif, was created 140$150 \mathrm{Ma}$ at the Pacific-Izanagi-Farallon (PIF) ridge-ridge-ridge triple junction. Moreover, the PIF triple junction was one of three triple junctions operating in close proximity at the time, as the nascent Pacific Plate (NPP) began to expand in size. This study suggests that the thermal conditions of the NPP, which likely resulted in a large area of thin lithosphere, could have significantly facilitated widespread mantle melting as well as the magmatic expression of any nearby mantle plume.
\end{abstract}

Plain Language Summary This study focuses on Shatsky Rise, a massive submarine magmatic plateau in the Pacific Ocean that covers an area comparable to California. Magnetics data show that this large igneous province (LIP) began to form 140-150 million years ago, near a setting in the plate tectonic system called a triple junction (TJ). TJs occur when three plate boundaries meet at a point; for Shatsky, the TJ consisted of three mid-ocean ridges. High magmatic fluxes inferred for Shatsky, and particularly for Tamu Massif in the southern portion of the LIP, led previous investigations to suggest that a mantle plume was important in plateau generation. However, although a large number of studies have examined the role of mantle plumes in LIP formation, few investigations address how plate boundary geometry could enhance LIP magmatism. Focusing on the latter, this study finds that the area where Tamu Massif was formed was characterized by thin lithosphere. A broad region of thin lithosphere could have facilitated widespread mantle melting and promoted mantle plume magmatism. Since there are many cases around the globe where LIPs formed near TJs, the relationship between plate boundary geometry and excess magmatic activity should be evaluated for those LIPs also.

\section{Geological Setting of Shatsky Rise}

Large igneous provinces (LIPs) are voluminous volcanic features that are emplaced over a short period of geologic time (e.g., Coffin \& Eldholm, 1994). In addition to being an important geological event, the generation of a LIP may affect atmospheric chemistry, oceanic circulation patterns, and biological cycles (Neal et al., 2019). This study focuses on Shatsky Rise (Figure 1), a LIP in the northwestern Pacific with an area roughly the size of California and a volume of $\sim 6.9 \times 10^{6} \mathrm{~km}^{3}$ (Zhang et al., 2016). Unlike most other Pacific plateaus, Shatsky Rise has a relatively well-constrained emplacement history because of comparatively dense isochron data spanning frequent magnetic reversals. These data suggest that the LIP formed near a ridge-ridge-ridge triple junction joining the Pacific, Izanagi, and Farallon plates (Nakanishi et al., 1999). Shatsky Rise is dominated by three prominent massifs, Tamu, Ori, and Shirshov (Figure 1). Papanin Ridge lies at the northern portion of the LIP. Seismic data for Shatsky Rise suggest crustal thickness of up to $\sim 30 \mathrm{~km}$ (Korenaga \& Sager, 2012).

Several lines of evidence indicate Shatsky Rise was emplaced in a near-ridge environment. For example, magnetic isochron patterns (Figure 1) show that Shatsky Rise formed at or close to a ridge-ridge-ridge triple junction (e.g., Nakanishi et al., 1999). Gravity analysis suggests Shatsky Rise was emplaced on young, weak lithosphere (Van Ark \& Lin, 2004). An ${ }^{40} \mathrm{Ar} /{ }^{39} \mathrm{Ar}$ date from drilling site 1213 in the southern portion of Tamu 


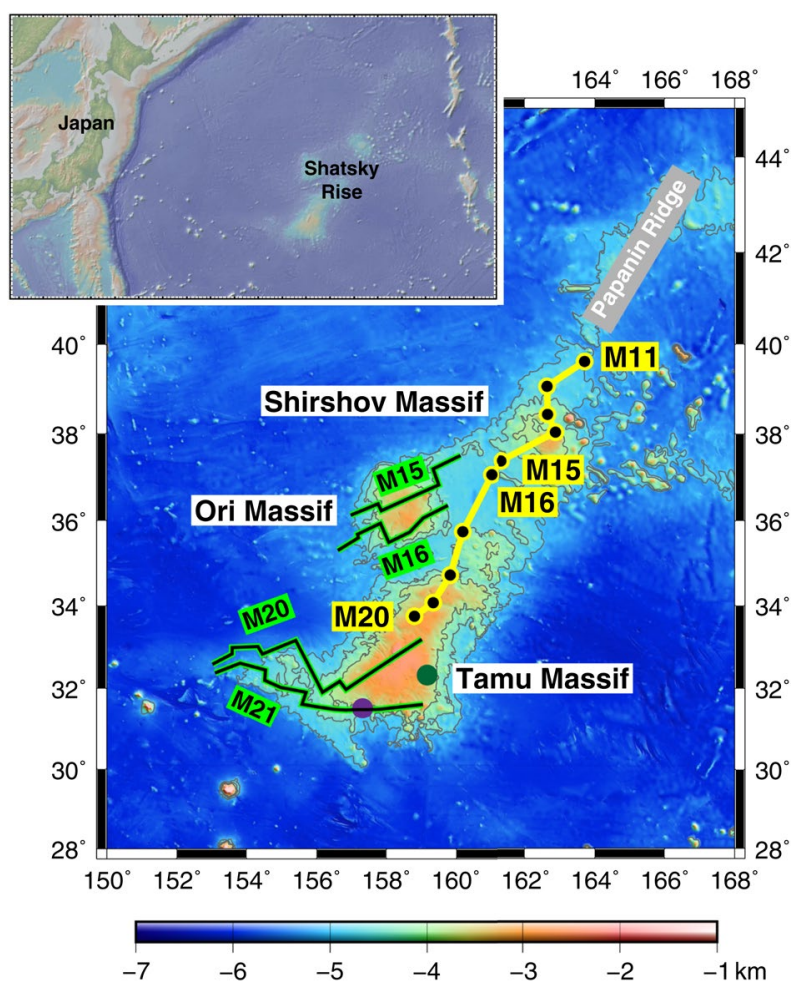

Figure 1. Seafloor depths at Shatsky Rise. (Inset) Setting of Shatsky Rise in the western Pacific Ocean. Figure was made with GeoMapApp (www. geomapapp.org), with seafloor depth data from Ryan et al. (2009). (Main panel) The northwestward migration of the Pacific-Izanagi-Farallon triple junction is shown by black-filled yellow dots, accompanied by the magnetic age at which the triple junction occupied each location. Isochrons bracketing the time of formation of Tamu and Ori massifs, which were extracted from Huang et al. (2018) and Sager et al. (2019), are highlighted in green. Locations of drill sites U1347 and 1213 are indicated with green and purple dots, respectively. Seafloor depths are from Smith and Sandwell (1997).
Massif is $144.6 \pm 0.8 \mathrm{Ma}$ (Mahoney et al., 2005), close to the age of the lithosphere surrounding that portion of the plateau. The youngest anomaly directly bounding Tamu Massif is M19 (Nakanishi et al., 1999), corresponding to a seafloor age of $146 \mathrm{Ma}$ (Ogg, 2012). Dates from the lower section of the lava flows at drilling site U1347 are similarly $143-145 \mathrm{Ma}$ (Geldmacher et al, 2014; Heaton \& Koppers, 2014; Tejada et al., 2016).

Relatively rapid magnetic reversals and dense isochron coverage allow reconstruction of the Pacific-Izanagi-Farallon (PIF) plate boundary during the formation of Shatsky Rise (Nakanishi et al., 1999; Sager et al., 1988) (Figure 2). During that period, ridge spreading rates were in the intermediate to fast range (Sager et al., 1988). Prior to Anomaly M22 (152 Ma), the triple junction was moving northwest in the Pacific plate reference frame (Sager et al., 1988). By Anomaly M20 (148 Ma) the triple junction had jumped approximately $800 \mathrm{~km}$ eastward, to the location of Tamu Massif (Sager et al., 1988, 1999). Subsequently, the PIF triple junction migrated northeastward and the rest of Shatsky Rise formed along the triple junction trace (Nakanishi et al., 1999; Sager et al., 1988, 1999). Northeastward-younging of the massifs is suggested by isochrons, which in some locations can be traced across Shatsky Rise (Nakanishi et al., 1999; Sager et al., 1999). For Ori and Shirshov massifs the youngest throughgoing magnetic lineation is Anomaly M14 (140 Ma), and Anomalies M10 to M1 (134-125 Ma) are found beneath Papanin Ridge. Emplacement rates appear to decrease northwards through the Ori and Shirshov massifs and drop off considerably for the Papanin Ridge (Sager et al., 1999).

\section{Plume Processes in the Emplacement of Shatsky Rise}

The importance of understanding the respective roles of plume dynamics and plate boundary processes in the formation of Shatsky Rise has been stressed by earlier investigations (e.g., Nakanishi et al., 1999; Sager et al., 1999, 2016). Calculations indicate that Shatsky volcanic flux was quite large, leading to the idea of involvement of a mantle plume head or geochemical heterogeneity (e.g., Sager \& Han, 1993; Sager et al., 1999, 2016; Nakanishi et al., 1999). Plume head volcanism has been invoked to explain the creation of Shatsky Rise as well as other LIPs (e.g., Campbell, 2005; Coffin \& Eldholm, 1994). A plume head is believed to be a large upwelling of buoyant material with a diameter of hundreds to perhaps a few thousand kilometers (e.g., Campbell \& Griffiths, 1990; Richards et al., 1989). The source region for plume heads is commonly thought to be the lower mantle, possibly in association with broad thermal, chemical, and/or seismic anomalies (e.g., Burke \& Torsvik, 2004; Cadio et al, 2011; Courtillot et al., 2003; Jackson \& Carlson, 2011; Larson, 1991). Plume heads may trail off into smaller plume tails, which are conduit-like structures that are potentially long-lived.

Several arguments support Shatsky's formation by a plume head (Sager, 2005), including rapid emplacement rates inferred for Tamu Massif. Also, the arrival of a broad plume head might have thermally weakened the lithosphere, contributing to the dynamics of the $\sim 800 \mathrm{~km}$ eastward jump of the triple junction. Additionally, the northeastward-younging of the Shatsky massifs, along with apparent decreasing flux, may reflect the transition from plume head to tail.

Geochemical data support of the plume hypothesis, however, is ambiguous. For example, Mahoney et al. (2005) performed $\mathrm{Nd}, \mathrm{Sr}$, and $\mathrm{Pb}$ isotopic analyses on basalts from Hole 1213B on the southwestern portion of Tamu Massif, and found ratios that were more similar to mid-ocean ridge basalt (MORB) than representative of ocean island basalt (OIB). Dredges D9 and D14 from Tamu and Ori massifs also have MORB-like isotopic ratios (Mahoney et al., 2005). Heydolph et al. (2014) found that Tamu Massif lavas are 

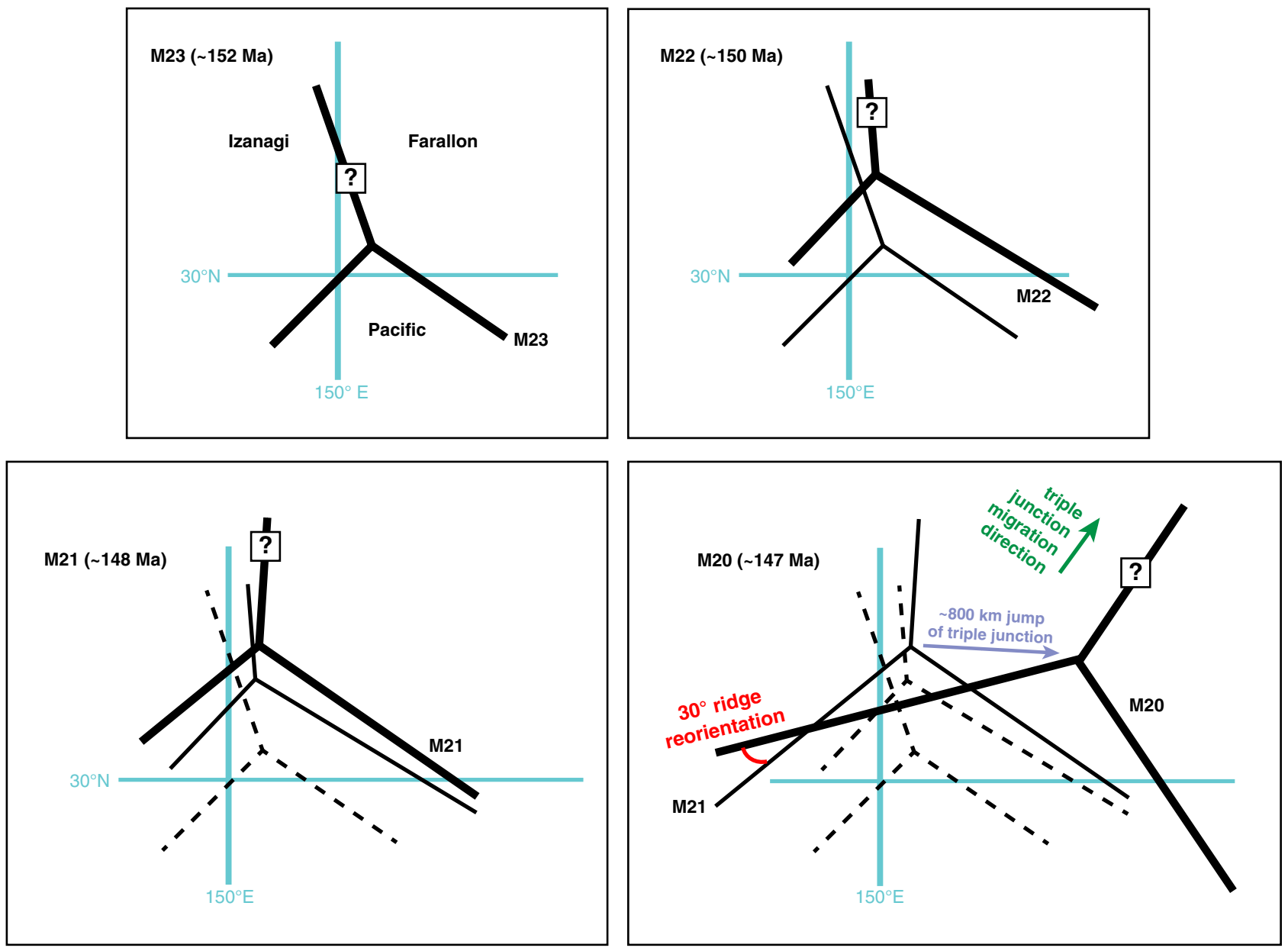

Figure 2. Schematic representations of the geometry of the Pacific-Izanagi-Farallon triple junction, prior to (M23-M21) and during (M20) the emplacement of Tamu Massif. These representations emphasize the changing azimuths of the three ridges. This figure also illustrates the $\sim 800 \mathrm{~km}$ eastward jump in the location of the triple junction at the time of Tamu Massif emplacement. Note that the orientation of the Izanagi-Farallon ridge cannot be directly constrained. However, based on the argument that the spreading rates of the three ridges were likely roughly similar (Seton et al., 2012), a ridge-ridge-ridge triple junction velocity vector solution suggests that the Izanagi-Farallon ridge likely was oriented roughly northward. Data on ridge locations and orientations were taken primarily from Nakanishi et al. (2015).

fairly homogenous. Increases in the degree of heterogeneity of Ori Massif lavas suggests the involvement of more mantle components over time, consistent with the transition from plume head to tail.

Using geochemical calculations, Husen et al. (2013) and Sano et al. (2012) determined that the degree of partial melting for Shatsky Rise basalts is 15\%-23\%, which extends to greater values than normal MORB. Sano et al. (2012) also calculate melting depths of greater than $30 \mathrm{~km}$, in the residual garnet field. Interestingly, though, investigations such as Sano et al. (2012) indicate that the thermal anomaly associated with Shatsky Rise magma was a maximum of $50^{\circ}-100^{\circ} \mathrm{C}$, which is lower than that found for mantle plumes such as Iceland $\left(\sim 200^{\circ} \mathrm{C}\right)$ and Hawaii $\left(\sim 300^{\circ} \mathrm{C}\right)$ (e.g., Putirka, 2008). Also, Korenaga and Sager (2012) suggest that a negative correlation between lower crustal seismic velocity and crustal thickness could indicate that the source mantle was cool, rather than hot.

Additional complications with the plume head hypothesis at Shatsky Rise involve magnetic isochron patterns and plate kinematics. First, in LIPs that form from focused volcanic centers, magnetic isochrons would generally be expected to reflect a centralized eruption pattern. However, Sager et al. (2019) found that isochrons across Shatsky Rise are linear, suggesting the excess volcanism was in association with a mid-ocean ridge. Second, a $20^{\circ}-30^{\circ}$ rotation of the Pacific-Izanagi ridge was originally interpreted to have occurred at the time of the initial Shatsky eruptions (Figure 2), and could therefore have been related to 
the arrival of a plume head. However, a more recent investigation (Nakaniski et al., 2015) suggests that the reorganization actually occurred several million years before Shatsky Rise formation, around Anomaly M22. Finally, Sager (2005) calculates that the arrival of a plume head within $\sim 800 \mathrm{~km}$ of the PIF triple junction is a statistically unlikely event. Compounding the statistical improbability are additional coincidences of oceanic plateaus and triple junctions throughout the geological history of the Pacific Ocean (Larson et al., 2002; Sager, 2005). Examples of LIPs at other global triple junctions include the Agulhas Plateau and the proto-Bouvet triple junction in the Indian Ocean (Uenzelmann-Neben \& Gohl, 2004), and the present-day Bouvet triple junction and an area of elevated seafloor in the southern Atlantic Ocean (e.g., Georgen et al., 2001; Ligi et al., 1999).

\section{Plate Boundary Processes in the Emplacement of Shatsky Rise}

Earlier numerical modeling studies focusing on mantle upwelling at ridge-ridge-ridge triple junctions found that fluid flow and temperature patterns can be markedly different in triple junction settings compared to where just two plates diverge (Georgen, 2008; Georgen \& Lin, 2002; Georgen \& Sankar, 2010). Additionally, in numerical models of plume-triple junction interaction, Dordevic and Georgen (2016) showed that the dispersion of plume material in the upper mantle is influenced by factors such as the distance of the plume conduit from the triple junction, and the azimuthal separation of the conduit and the slowest-spreading ridge. Thus, in settings where a triple junction and mantle plume interact, the geometry of the plate boundary system can both modulate patterns of excess magmatism and influence the size and shape of an oceanic plateau.

Compared to these earlier studies, which modeled specific cases of plume-triple junction fluid dynamical interactions, this investigation puts forward a generalized tectonic mechanism for the unusually common coincidence of triple junctions and LIPs globally (e.g., Whittaker, 2019), using Shatsky Rise as a type example. As noted earlier, Shatsky Rise formed during a period of relatively rapid magnetic reversals, and hence it is well-suited to furthering the understanding of LIP magmatic processes at a triple junction. Insights from Shatsky Rise can be applied to other LIPs that formed near triple junctions, particularly those LIPs that were generated during the Cretaceous normal superchron or that lack substantial magnetics data because of subduction processes.
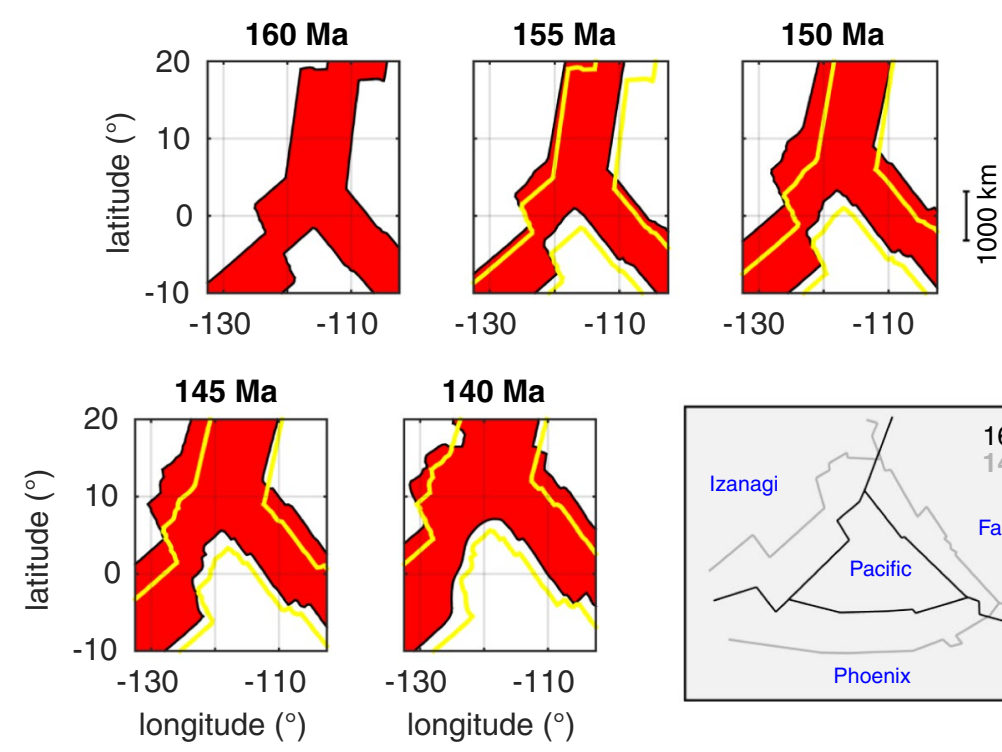

$140 \mathrm{Ma}$
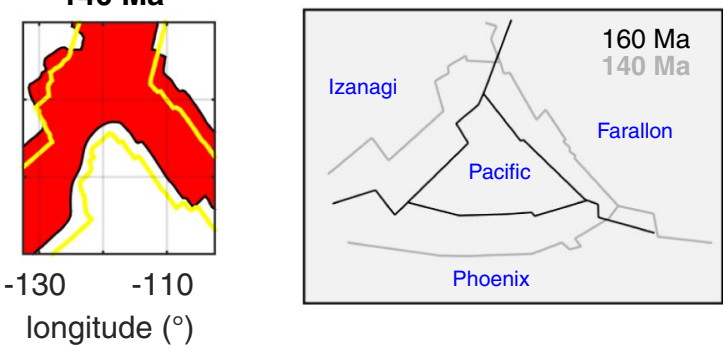

Figure 3. Thin lithosphere near the Pacific-Izanagi-Farallon triple junction during the formation of Shatsky Rise. (Bottom right panel) The changing configuration of the Pacific Plate and surrounding plates, bracketing the time of Tamu Massif formation. Data are from Seton et al. (2012). (Other panels) Lithospheric thickness calculated using the conductive cooling formula of Parsons and Sclater (1977) and ages from Seton et al. (2012). Red color indicates lithosphere less than $40 \mathrm{~km}$ thick. A value of $40 \mathrm{~km}$ was selected as a rough cutoff based on calculations presented in Mittelstaedt et al (2011); below $40 \mathrm{~km}$, ridge jumps are more likely to occur during plume-ridge interactions. Yellow lines show the boundaries of the thin lithosphere from the prior age panel, for reference. 
At the time of formation of Shatsky Rise, the PIF triple junction was one of three triple junctions operating in close proximity, as the nascent Pacific Plate (NPP) began to develop and expand in size (Seton et al., 2012). Figure 3 shows lithospheric thickness calculated from seafloor age for the PIF triple junction, based on the conductive cooling formula of Parsons and Sclater (1977) and ages from Seton et al. (2012). Although this is a simple approach to determining lithospheric thickness, it illustrates how a spatially widespread area around the migrating PIF triple junction was characterized by a thin thermal boundary later. In the setting of the NPP, large bands of thin lithosphere surrounding the plate boundaries of the PIF triple junction may have facilitated widespread plume magmatism.

In addition to being characterized by thermally weak lithosphere, the PIF triple junction also migrated northeastward during the formation of Shatsky Rise (Figure 1). As the triple junction jumped to the northeast, it progressively propagated into regions of young lithosphere where brittle deformation might have

(a)

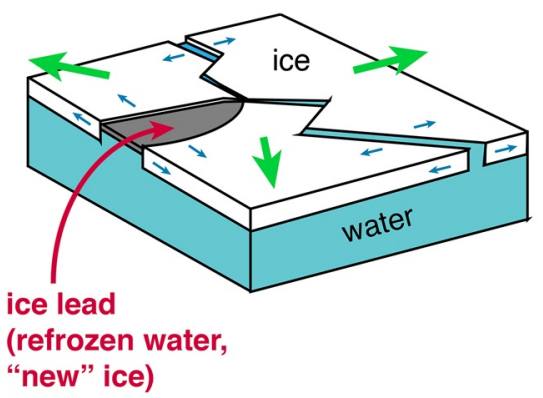

(b)

Simple ridge divergence
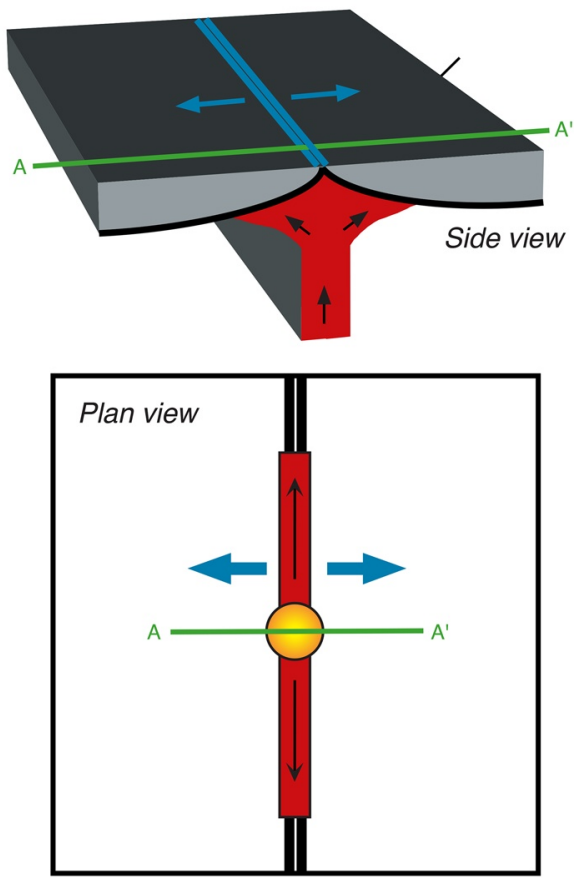

With tectonic lead
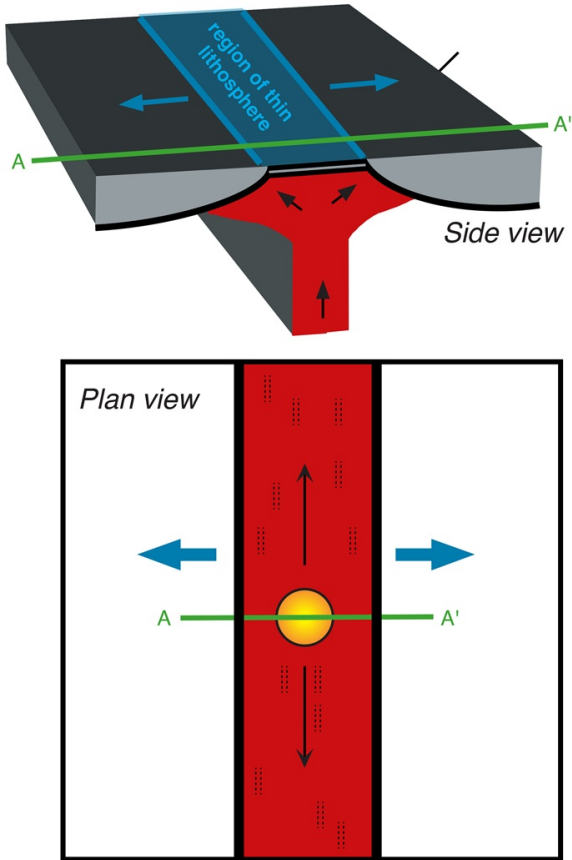

Figure 4. (a) An ice lead is a fracture in sea ice that exposes an open, quasi-linear area of seawater directly to the atmosphere. By analogy, this investigation defines a "tectonic lead" to be a portion of the thermal boundary layer that has thinner than expected lithospheric thickness, caused by factors such as tectonic setting, ridge geometry and azimuth, and plate boundary forces. (b) Plume-ridge interaction along a ridge with a simple, traditional divergence pattern and narrow neo-volcanic zone (left) compared to plume-ridge interaction in an area with a tectonic lead (right). Dashed double lines schematically represent disorganized, transient spreading segments within the tectonic lead that rapidly evolve because of thin lithosphere, hot mantle temperatures, and changing plate boundary forces. 


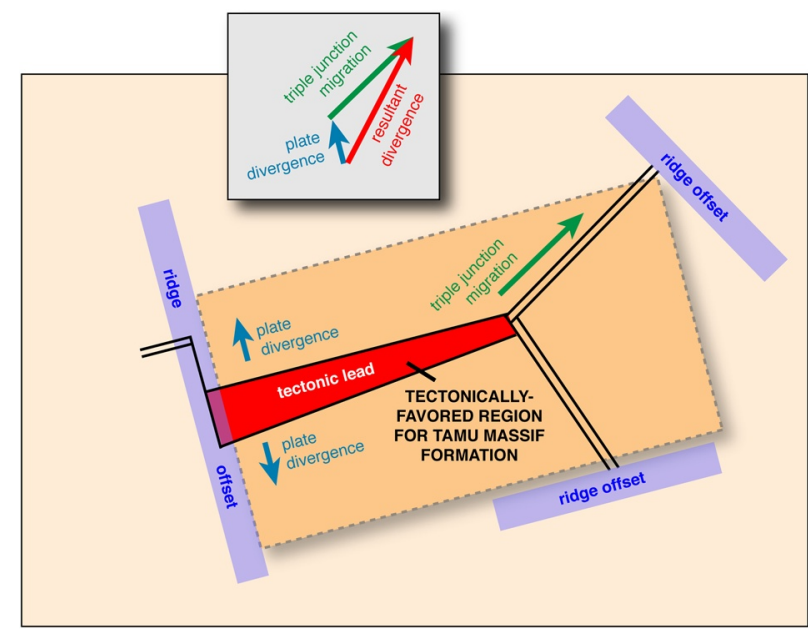

Figure 5. Cartoon depicting plate boundary processes at the PacificIzanagi-Farallon triple junction at the time of Tamu Massif formation. Peach color schematically represents a broad area of young, thin, weak lithosphere surrounding the triple junction. Inset shows relative plate motion vectors in the direction of seafloor spreading (blue arrows) and the general direction of triple junction migration (green arrow). Factors such as rapid triple junction migration to the northeast and propitious ridge orientation may have encouraged the development of a zone along the Pacific-Izanagi ridge (labeled as "tectonic lead") that had low lithospheric thickness. Within the tectonic lead, large volumes of mantle may have undergone melting, and plume-ridge interaction could have been vigorous. been relatively suppressed. Additionally, extension along the Pacific-Izanagi spreading center may have been augmented because of its azimuth; plate spreading vectors along this ridge branch were roughly subparallel to the direction of triple junction migration. Such enhanced extension could suggest that excess volcanism would have tended to occur along the Pacific-Izanagi ridge rather than the other two ridge branches. In fact, magnetics investigations of Tamu Massif (Sager et al., 2019) and Ori Massif (Huang et al., 2018) found that both structures were primarily emplaced along the Pacific-Izanagi ridge (Figure 1).

\section{Geodynamic Setting of Tamu Massif Formation}

In Figure 4, we present a schematic representation of a possible mode of interaction between the Pacific-Izanagi ridge and the plume involved in Tamu Massif generation. Plume-ridge interaction studies have investigated how plume material disperses under the axis of a single mid-ocean ridge, with a relatively narrow neo-volcanic zone (Figure 4b) (e.g., Ito et al., 2003 and references therein). However, this study postulates that the style of divergence along the Pacific-Izanagi ridge at the time of massif emplacement was somewhat different than simple seafloor spreading along a well-defined ridge axis. By way of analogy, an ice lead is a fracture in sea ice that exposes an open, quasi-linear area of seawater directly to the atmosphere (Figure 4a). Broadly speaking, an ice lead develops from a crack to an open-water feature because of changes in the force vector balance on the crack that promote opening or divergence. In this investigation, we define a "tectonic lead" to be a portion of the thermal boundary layer that has thinner than expected lithospheric thickness (Figure $4 \mathrm{~b}$ ), because of a balance of plate boundary forces that causes extension and magmatism over a broader area than a simple neo-volcanic zone.

The tectonic lead style of plate divergence would be favored in cases like the Pacific-Izanagi ridge, because of factors such as relatively fast spreading rates, a triple junction plate setting, rapid triple junction migration, and preferential orientation of the ridge azimuth (Figure 5). Beneath the tectonic lead, a large volume of mantle could have undergone partial melting, resulting in a spatially extensive area of thickened crust, shallowed seafloor, and an oceanic plateau. Within the lead, rapid reorganization of plate boundary forces could result in disorganized spreading, perhaps with multiple centers of spreading acting at the same time, as well as widespread ridge propagation.

As discussed above, previous studies (Huang et al., 2018; Sager et al., 2019) found that the formation of both Tamu Massif and Ori Massif was concentrated along the Pacific-Izanagi ridge, which is consistent with the plate boundary processes in the schematic representation of Figure 5. Moreover, magnetic anomaly maps presented in Sager et al. (2019) show that isochron spacing along the Pacific-Izanagi ridge during Tamu Massif emplacement is unusually wide, as well as curved along some portions. These isochron patterns are consistent with the notion of seafloor extension being accommodated over a widespread area, across which small ridge segments might rapidly form and then become inactive as stress fields rotate and change. As an additional note, any factors that could have contributed to greater degrees of magmatism in association with the creation of the NPP, such as higher temperature melting than is seen in modern MORB (e.g., Fisk \& Kelley, 2002), would have compounded the excess crustal production at the inferred tectonic lead.

Overall, this investigation points to the potential importance of ridge-related processes in the emplacement of LIPs at spreading centers (Whittaker, 2019), and particularly to the role that triple junction plate boundary geometry could play in creating excess crustal thickness over a broad area. Since many other global LIPs formed at triple junctions (e.g., Larson et al., 2002; Sager, 2005; Uenzelmann-Neben \& Gohl, 2004) the results of this study may indicate the value of examining lithospheric thermal structure during the emplacement of other oceanic plateaus as well. 


\section{Conflict of Interest}

The authors have no conflicts of interest.

\section{Data Availability Statement}

Data for this paper were extracted from Nakanishi et al. (2015), Huang et al. (2018), and Sager et al. (2019); data sets used are from Smith and Sandwell (1997), Ryan et al. (2009), and Seton et al. (2012).

\section{References}

This study was funded by National Science Foundation (NSF) grant OCE1658069 to J. Georgen. The authors greatly appreciate the thoughtful comments of A. Briais and an anonymous reviewer.

Burke, K., \& Torsvik, T. H. (2004). Derivation of large igneous provinces of the past 200 million years from long-term heterogeneities in the deep mantle. Earth and Planetary Science Letters, 227, 531-538. https://doi.org/10.1016/j.epsl.2004.09.015

Cadio, C., Panet, I., Davaille, A., Diament, M., Metivier, L., \& de Viron, O. (2011). Pacific geoid anomalies revisited in light of thermochemical oscillating domes in the lower mantle. Earth and Planetary Science Letters, 306, 123-135. https://doi.org/10.1016/j.epsl.2011.03.040

Campbell, I. H. (2005). Large igneous provinces and the mantle plume hypothesis. Elements, 1(5), 265-269. https://doi.org/10.2113/ gselements.1.5.265

Campbell, I. H., \& Griffiths, R. W. (1990). Implications of mantle plume structure for the evolution of flood basalts. Earth and Planetary Science Letters, 99, 79-93. https://doi.org/10.1016/0012-821x(90)90072-6

Coffin, M. F., \& Eldholm, O. (1994). Large igneous provinces: Crustal structure, dimensions, and external consequences. Reviews of Geophysics, 32, 1-36. https://doi.org/10.1029/93rg02508

Courtillot, V., Davaille, A., Besse, J., \& Stock, J. (2003). Three distinct types of hotspots in the Earth's mantle. Earth and Planetary Science Letters, 205, 295-308. https://doi.org/10.1016/s0012-821x(02)01048-8

Dordevic, M., \& Georgen, J. (2016). Dynamics of plume - Triple junction interaction: Results from a series of three-dimensional numerical models and implications for the formation of oceanic plateaus. Journal of Geophysical Research, 121, 1316-1342. https://doi. org/10.1002/2014jb011869

Fisk, M., \& Kelley, K. A. (2002). Probing the Pacific's oldest MORB glass: Mantle chemistry and melting conditions during the birth of the Pacific Plate. Earth and Planetary Science Letters, 202, 741-752. https://doi.org/10.1016/s0012-821x(02)00760-4

Geldmacher, J., vanden Bogaard, P., Heydolph, K., \& Hoernle, K. (2014). The age of the Earth's largest volcano: Tamu Massif on Shatsky Rise (northwest Pacific Ocean). International Journal of Earth Sciences, 103, 2351-2357. https://doi.org/10.1007/s00531-014-1078-6

Georgen, J. E. (2008). Mantle flow and melting beneath oceanic ridge-ridge-ridge triple junctions. Earth and Planetary Science Letters, 270, 231-240. https://doi.org/10.1016/j.epsl.2008.03.040

Georgen, J. E., \& Lin, J. (2002). Three-dimensional passive flow and temperature structure beneath oceanic ridge-ridge-ridge triple junctions. Earth and Planetary Science Letters, 204, 115-132. https://doi.org/10.1016/s0012-821x(02)00953-6

Georgen, J. E., Lin, J., \& Dick, H. J. B. (2001). Evidence from gravity anomalies for interactions of the Marion and Bouvet hotspots with the Southwest Indian Ridge: Effects of transform offsets. Earth and Planetary Science Letters, 187, 283-300. https://doi.org/10.1016/ s0012-821x(01)00293-x

Georgen, J. E., \& Sankar, R. D. (2010). Effects of ridge geometry on mantle dynamics in an oceanic triple junction region: Implications for the Azores Plateau. Earth and Planetary Science Letters, 298, 23-34. https://doi.org/10.1016/j.epsl.2010.06.007

Heaton, D. E., \& Koppers, A. A. A. P. (2014). Constraining the rapid construction of TAMU Massif at an 14 Myr old triple junction, Shatsky Rise. 2014 Goldschmidt conference.

Heydolph, K., Murphy, D. T., Geldmacher, J., Romanova, I. V., Greene, A., Hoernle, K., et al. (2014). Plume versus plate origin for the Shatsky Rise oceanic plateau (NW Pacific): Insights from Nd, Pb, and Hf isotopes. Lithos, 200-201, 49063.

Huang, Y., Sager, W. W., Tominaga, M., Greene, J. A., Zhang, J., \& Nakanishi, M. (2018). Magnetic anomaly map of Ori Massif and its implications for oceanic plateau formation. Earth and Planetary Science Letters, 501, 46-55. https://doi.org/10.1016/j.epsl.2018.08.029

Husen, A., Almeev, R. R., Holtz, F., KoepkeSano, J. T., Mengel, K., \& Mengel, K. (2013). Geothermobarometry of basaltic glasses from the Tamu Massif, Shatsky Rise oceanic plateau. Geochemistry, Geophysics, Geosystems, 14, 3908-3928. https://doi.org/10.1002/ggge.20231

Ito, G., Lin, J., \& Graham, D. (2003). Observational and theoretical studies of the dynamics of mantle plume-mid-ocean ridge interaction. Reviews of Geophysics, 41(4). https://doi.org/10.1029/2002rg000117

Jackson, M. J., \& Carlson, R. W. (2011). An ancient recipe for flood-basalt genesis. Nature, 476, 316-319. https://doi.org/10.1038/ nature10326

Korenaga, J., \& Sager, W. W. (2012). Seismic tomography of Shatsky Rise by adaptive importance sampling. Journal of Geophysical Research, 117. https://doi.org/10.1029/2012JB009248

Larson, R. L. (1991). Geological consequences of superplumes. Geology, 19, 963-966. https://doi.org/10.1130/0091-7613(1991)019 $<0963: \cos >2.3 . \operatorname{co} ; 2$

Larson, R. L., Pockalny, R. A., Viso, R. F., Erba, E., Abrams, L. J., Luyendyk, B. P., et al. (2002). Mid-Cretaceous tectonic evolution of the Tongareva triple junction in the southwestern Pacific Basin. Geology, 30, 67-70. https://doi.org/10.1130/0091-7613(2002)030<006 7:mcteot>2.0.co;2

Ligi, M., Bonatti, E., Bortoluzzi, G., Carrara, G., Fabretti, P., Gilod, D., et al. (1999). Bouvet Triple Junction in the South Atlantic: Geology and evolution. Journal of Geophysical Research, 104, 29365-29385. https://doi.org/10.1029/1999jb900192

Mahoney, J. J., Duncan, R. A., Tejada, M. L. G., Sager, W. W., \& Bralower, T. J. (2005). Jurassic- Cretaceous boundary age and mid-oceanridge-type mantle source for Shatsky Rise. Geology, 33, 185-188. https://doi.org/10.1130/g21378.1

Mittelstaedt, E., Ito, G., \& van Hunen, J. (2011). Repeat ridge jumps associated with plume-ridge interaction, melt transport, and ridge migration. Journal of Geophysical Research, 116(B1). https://doi.org/10.1029/2010jb007504

Nakanishi, M., Sager, W. W., \& Klaus, A. (1999). Magnetic lineations within Shatsky Rise, northwest Pacific Ocean: Implications for hot spot-triple junction interaction and oceanic plateau formation. Journal of Geophysical Research, 104, 7539-7556. https://doi. org/10.1029/1999jb900002 
Nakanishi, M., Sager, W. W., \& Korenaga, J. (2015). Reorganization of the Pacific-Izanagi-Farallon triple junction in the Late Jurassic: Tectonic events before the formation of Shatsky Rise. In C. Neal, W. Sager, T. Sano, \& E. Erba (Eds.), The origin, evolution, and environmental impacts of oceanic large igneous provinces (Vol. 511, pp. 85-101). Geological Society of America. https://doi.org/10.1130/2015.251105

Neal, C. R., Coffin, M. F., \& Sager, W. W. (2019). Contributions of scientific ocean drilling to understanding the emplacement of submarine large igneous provinces and their effects on the environment. Oceanography, 32(1), 176-192. https://doi.org/10.5670/oceanog.2019.142

Ogg, J. (2012). Geomagnetic Polarity Time Scale. In F. M. Gradstein, J. G. Ogg, M. D. Schmitz, \& G. M. Ogg (Eds.), The geologic time scale (pp. 85-113). Elsevier. https://doi.org/10.1016/b978-0-444-59425-9.00005-6

Parsons, B., \& Sclater, J. G. (1977). An analysis of the variation of ocean floor bathymetry and heat flow with age. Journal of Geophysical Research, 82(5), 803-827. https://doi.org/10.1029/jb082i005p00803

Putirka, K. (2008). Excess temperatures at ocean islands: Implications for mantle layering and convection. Geology, 36, 283-286. https:// doi.org/10.1130/g24615a.1

Richards, M. A., Duncan, R. A., \& Courtillot, V. E. (1989). Flood basalts and hot-spot tracks: Plume heads and tails. Science, 246, 103-107. https://doi.org/10.1126/science.246.4926.103

Ryan, W. B. F., Carbotte, S. M., Coplan, J. O., O'Hara, S., Melkonian, A., Arko, R., et al. (2009). Global multi-resolution topography synthesis. Geochemistry, Geophysics, Geosystems, 10, Q03014. https://doi.org/10.1029/2008GC002332

Sager, W. W (2005). What built Shatsky Rise, a mantle plume or ridge processes? In G R J H FoulgerNatland, D. C Presnall, \& D. L Anderson (Eds.), Plates, plumes, and paradigms, spec (Vol. 388, pp. 721-733). Paper - Geol. Soc. Am. https://doi.org/10.1130/0-8137-2388-4.721

Sager, W. W., \& Han, H.-C. (1993). Rapid formation of the Shatsky Rise oceanic plateau inferred from its magnetic anomaly. Nature, 364, 610-613. https://doi.org/10.1038/364610a0

Sager, W. W., Handschumacher, D. W., Hilde, T. W. C., \& Bracey, D. R. (1988). Tectonic evolution of the northern Pacific plate and Pacific-Farallon Izanagi triple junction in the Late Jurassic and Early Cretaceous (M21-M10). Tectonophysics, 155, 345-364. https://doi. org/10.1016/0040-1951(88)90274-0

Sager, W. W., Huang, Y., Tominaga, M., Greene, J. A., Nakanishi, M., \& Zhang, J. (2019). Oceanic plateau formation by seafloor spreading implied by Tamu Massif magnetic anomalies. Nature Geoscience, 12(8), 661-666. https://doi.org/10.1038/s41561-019-0390-y

Sager, W. W., Kim, J., KlausNakanishi, A. M., Khankishieva, L. M., \& Khankishieva, L. M. (1999). Bathymetry of Shatsky Rise, northwest Pacific Ocean: Implications for ocean plateau development at a triple junction. Journal of Geophysical Research, 104, 7557-7576. https:// doi.org/10.1029/1998jb900009

Sager, W. W., Sano, T., \& Geldmacher, J. (2016). Formation and evolution of Shatsky Rise oceanic plateau: Insights from IODP Expedition 324 and recent geophysical cruises. Earth-Science Reviews, 159, 306-336. https://doi.org/10.1016/j.earscirev.2016.05.011

Sano, T., Shimizu, K., Ishikawa, A., Senda, R., Chang, Q., Kimura, J.-L., et al. (2012). Variety and origin of magmas on Shatsky Rise, northwest Pacific Ocean. Geochemistry, Geophysics, Geosystems, 13. https://doi.org/10.1029/2012GC004235

Seton, M., Müller, R. D., Zahirovic, S., Gaina, C., Torsvik, T., Shephard, G., et al. (2012). Global continental and ocean basin reconstructions since 200 Ma. Earth-Science Reviews, 113(3-4), 212-270. https://doi.org/10.1016/j.earscirev.2012.03.002

Smith, W. H., \& Sandwell, D. T. (1997). Global sea floor topography from satellite altimetry and ship depth soundings. Science, 277(5334), 956-1962. https://doi.org/10.1126/science.277.5334.1956

Tejada, M. L. G., Geldmacher, J., Hauff, F., Heaton, D., Koppers, A. A., Garbe-Schönberg, D., et al. (2016). Geochemistry and age of Shatsky, Hess, and Ojin Rise seamounts: Implications for a connection between the Shatsky and Hess Rises. Geochimica et Cosmochimica Acta, 185, 302-327. https://doi.org/10.1016/j.gca.2016.04.006

Uenzelmann-Neben, G., \& Gohl, K. (2004). The Agulhas Ridge, South Atlantic: The peculiar structure of a fracture zone. Marine Geophysical Researches, 25, 305-319. https://doi.org/10.1007/s11001-005-1338-8

Van Ark, E., \& Lin, J. (2004). Time variation in igneous volume flux of the Hawaii-Emperor hot spot seamount chain. Journal of Geophysical Research, 109, B11401. https://doi.org/10.1029/2003jb002949

Whittaker, J. M. (2019). Plateaus from seafloor spreading. Nature Geoscience, 12(8), 587-588. https://doi.org/10.1038/s41561-019-0416-5

Zhang, J., Sager, W. W., \& Korenaga, J. (2016). The seismic Moho structure of Shatsky rise oceanic plateau, northwest Pacific Ocean. Earth and Planetary Science Letters, 441, 143-154. https://doi.org/10.1016/j.epsl.2016.02.042 